\title{
LINGUAGEM E PODER EM Nós, OS Do MAKULUSU, DE JOSÉ LUANDINO VIEIRA
}

Enio Gontijo de Lacerda

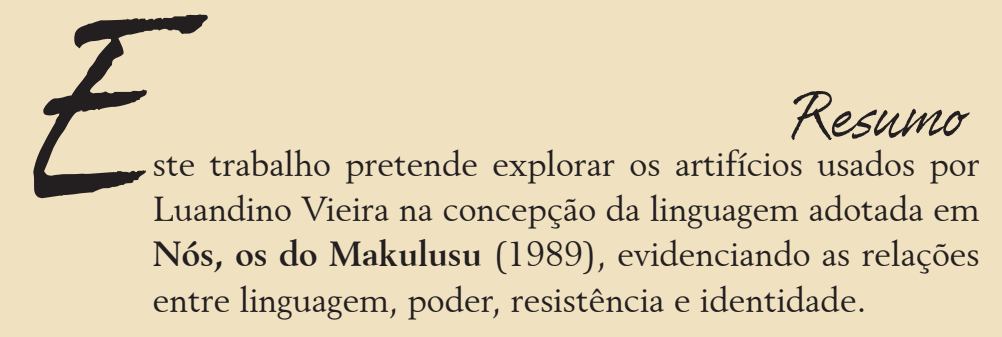

Palavras-chave: Luandino Vieira. Linguagem. Poder. Resistência. Identidade.

Uma das coisas que mais chamam a atenção na escritura de José Luandino é seu caráter experimental. A partir do momento em que o leitor começa a passar os olhos pelas primeiras linhas de seu romance Nós, os do Makulusu (1989), se sente completamente perdido e esta sensação não passa tão cedo. Ao contrário, acompanha-o ao longo da narrativa.

Em seu livro Seis passeios pelos bosques da ficção (1994), Umberto Eco usa a palavra bosque como termo alegórico de um espaço onde permanece um tipo de leitor, chamado por Eco de modelo, que está tentando decifrar o texto, perdido, examinando detidamente os sendeiros do caminho e procurando uma saída. Poderíamos dizer ainda que ele está sondando o caminho e o único roteiro de que dispõe são as pistas lançadas pelo autor, um autor também chamado de modelo. Pois bem, tomemos o modelo proposto por Eco na elaboração de um similar proposto por Luandino Vieira. No lugar da palavra bosque usaremos o termo via crucis ao nos referirmos à caminhada trilhada pelo personagem Mais Velho, que narra a história em primeira pessoa, e também pelo leitor, responsável direto pelo preenchimento das lacunas deixadas no 
texto. Faz-se curiosa a presença do símbolo da cruz: está na igreja, no nome do cemitério "Alto das Cruzes" e no nome do musseque, Makulusu, que também significa cruz.

Um dos elementos que nos conduz nesta via crucis é o movimento de vai e vem, como as ondas do mar, suscitando uma temporalidade cíclica, executado pelo caixão de Maninho enquanto é conduzido ora na igreja, ora nas ruas, ora no cemitério. Maninho é o irmão mais novo do narrador-personagem Mais Velho. Sabemos que ele está morto desde o início da história, em decorrência de uma emboscada, na luta pela libertação de Angola, da qual participava como membro do exército colonial. Sabemos também que sua morte pesa como um trauma sobre seu irmão, Mais Velho, cujas memórias (des)norteiam toda a narrativa, que é completamente fragmentada, para não dizer caótica, pois não apresenta uma ordem cronológica e é costurada de flashbacks e flashforwards, ou seja, avança e retrocede o tempo todo.

Assim, na narrativa memorialística de Mais Velho, Maninho ora aparece vivo, ora morto. O passado, ou sequência de histórias enfeixadas em diferentes fases do passado das personagens, se mistura, se embaralha e se une ao discurso de Mais Velho, numa força lancinante, muitas vezes desorientando o leitor, especialmente com relação ao foco narrativo e à estrutura temporal. Segundo Eco, analisando a escrita de Proust: "os flashbacks passam quase despercebidos e parecem reparar um esquecimento do autor, ao passo que um flashforward constitui uma impaciência narrativa" (ECO, 1994, p. 36), já que "constantemente se é obrigado a voltar atrás algumas páginas para descobrir se está no presente ou no passado relembrado". (ECO, 1994, p. 38).

O estilo de Luandino também nos remete um pouco a romances de William Faulkner como O som e a fúria (2004) e Enquanto agonizo (2009) com relação à estrutura temporal e mesmo à composição dos personagens e seus conflitos em família. Mas ao contrário de Faulkner, que trabalha com a ação dividida em capítulos, também na primeira pessoa, mas com narradores diversos, cada um contando sua versão dos acontecimentos portanto, um quadro de personagens com diferentes pontos de vista -, Luandino centraliza o discurso na voz de um narrador-personagem, Mais Velho, embora outros intervenham esporadicamente na narrativa, através de suas falas e mesmo atravessando o discurso do narrador-personagem. 
O discurso de Mais Velho possui, como característica, um forte traço polifônico, desencadeado pela multiplicidade de vozes que se lhe atravessam, revelando apontamentos sociais, políticos e psicológicos que, muitas vezes, são inteiramente contraditórios, apontando para outros segmentos de ordem filosófica ou sócio-política e estabelecendo um diálogo entre si. Em sua narrativa, Mais Velho executa aquela liberdade do autor, apontada por Bakhtin quando explica que "O autor está livre de uma linguagem única, ele não se autodefine no plano linguístico, ele pode transferir suas intenções de um plano linguístico a outro, misturar linguagens, falar por si na linguagem de outrem e por outrem na sua própria linguagem." (BAKHTIN, 1.993, p. 109). Nesse sentido, a linguagem de Mais Velho desencadeia uma série de contradições, já que suas opiniões se divergem e divergem também de uma identidade única, totalizadora, seja ela do personagem ou da narrativa.

A escrita de Luandino Vieira nos faz mergulhar numa viagem vertiginosa pelo enredo e, mais precisamente, pelo trabalho com a linguagem, o que acreditamos que deva ser feito na perspectiva de Eco, para quem "a dissecação de um texto não pode matar sua magia"; ao contrário, deve nos aproximar mais, nos colocar em contato com a obra que se abre e se manifesta em todas as suas possibilidades, se desdobrando e multiplicando seus sentidos, como um caleidoscópio, muitas vezes paradoxal por não manter um comprometimento com a verdade, e por isso mesmo plural.

Assim, vemos que Nós, os do Makulusu, muitas vezes, apresenta-se como uma construção caleidoscópica. Isso acontece, por exemplo, na composição de seus personagens. Observemos os personagens Mais Velho e Maninho. O primeiro luta pela independência do país ao lado dos negros, mas repudia sua comida e não se deita com mulheres negras, ao passo que o irmão Maninho luta ao lado dos brancos, mas convive com os negros e sua namorada é mulata. Tomemos, como exemplo, a seguinte fala de Maninho: "E então Mais Velho? Lês Marx e comes bacalhau assado, não é? Não te deitas com negras e mulatas - a tua cunhada é mulata [...] Espalha os teus panfletos que eu vou matar negros" (VIEIRA, 1989, p. 28). Esta fala mostra como a escrita luandina se constrói de maneira a eliminar a utopia romanesca de uma trama onde os personagens são fechados e categorizados como heróis e vilões. Maninho e Mais Velho, por serem personagens tão complexos e contraditórios, exibem, assim, um caráter e uma constituição extremamente humanizados. 
Um outro aspecto interessante que pode ser observado na obra é a questão do cruzamento de duas culturas distintas em uma determinada zona de contato, resultando em uma cultura híbrida. Em Nós, os do Makulusu temos a presença do branco representada especialmente pela família de Mais Velho; a presença do negro centrada em Kibiaka, além de outros personagens secundários; e Paizinho, o "encardido de carapinha loura", aparentemente filho de Paulo, o pai de Mais Velho com uma lavadeira negra. Com isso, a própria família de Mais Velho é uma mostra do cruzamento resultante entre as duas culturas. De acordo com Stuart Hall, essas pessoas "são obrigadas a negociar com as novas culturas em que vivem, sem simplesmente serem assimiladas por elas e sem perder completamente suas identidades", pois "elas não são e nunca serão unificadas no velho sentido, porque elas são, irrevogavelmente, o produto de várias histórias e culturas interconectadas". (HALL, 2.006, p.88/89).

A figura do branco, que simboliza o colonizador, está na família constituída pelo pai, a mãe de Mais Velho, seu irmão Maninho e uma irmã. Mas mesmo assim, quando se diz colonizador, esta palavra pode resultar em um estranhamento, pois não se trata de uma família abastada, dona de latifúndios, etc. Ao contrário, nas divagações feitas por Mais Velho não aparece qualquer elemento que evidencie isso, mas sim a figura de uma mãe submissa, que não tem empregada para ajudá-la e está sempre com as unhas sujas, enegrecidas pelo trabalho doméstico. Mais Velho e Maninho aparecem sempre brincando ao lado de Paizinho e Kibiaka e, muitas vezes, são duramente repreendidos pelo pai, que se mostra um homem extremamente intolerante e preconceituoso. Nessas brincadeiras entre as crianças, sempre em evidência na sucessão de flashbacks e fashforwards, torna-se claro o diálogo em profusão e desenvolvimento entre as culturas e a mescla advinda daí. Este cruzamento se faz notar especialmente na ordem do discurso, pois é nele que estão centrados todos os elementos que nos conduzem a tais considerações. A cena mais representativa nesse sentido é a do pacto de sangue feito entre as quatro crianças:

O canivete nas mãos, o pequeno corte no pulso, um, dois, três, quatro, o sangue em pequeninas gotas, que o Paizinho sabe fazer o golpe, e aí lhe vejo primeira vez o nosso sangue: o que deu os meus olhos no Maninho e no Paizinho e a mim, um líquido simples e esfregado no ar e é a primeira vez que vejo o sangue de Maninho [...] Vento por cima das cabeças, pemba nas mãos, amassada 


\section{Enio Gontijo de Lacerda}

no sangue, olhos brancos de flores de mupinheira, vermelhos olhos e bagas de cassuneira a olharem os nossos pulsos colados uns nos outros e as vozes vêm eu oiço olho o espelho dos quatro olhos que me olham e me olharam lá também. (VIEIRA, 1989, p. 49).

Nele fica evidente a forma como estas culturas literalmente trocam fuidos, como elas se interceptam e fica ainda sugerida a condição mestiça de Paizinho, elemento resultante deste cruzamento. Destaca-se aí também um elemento de extrema importância na concepção do discurso: a linguagem usada por Luandino Vieira para tratar dessas mesclas culturais e étnicas, fator absolutamente relevante para que se compreenda por inteiro sua proposta estética. O trabalho de linguagem será identificado no campo semântico e na estrutura sintática das frases.

No plano semântico observa-se na escrita luandina uma clara intenção de "rasurar" a palavra, especialmente em língua portuguesa, multiplicando o teor de suas significações. É interessante notar a dimensão da palavra e suas nuances em Nós, os do Makulusu. Paizinho, por exemplo, nunca é tachado de mulato e sim "encardido" ou "miúdo que não é bem preto, parece um branco que não se lava há muito tempo". (VIEIRA, 1989, p. 21). Mais Velho se refere a Maninho como "meu puro irmão amigo". (VIEIRA, 1989, p. 25). Vê-se aí novo contraste, pois o adjetivo puro pode fazer alusão tanto à inocência do irmão como ao fato de ele ser seu irmão por parte de pai e mãe, diferenciando-o assim de Paizinho. Mais à frente "tu, minha Maria do liso nome e suave sem ruga doutro nome a estragar-lhe, do suave e liso loiro corpo..." (VIEIRA, 1989, p.55), também é a forma como se refere à irmã.

A subversão da sintaxe tem como aspectos principais a ausência de pontuação em alguns trechos, especialmente com a abolição de vírgulas e pontos, recurso usado por muitos escritores, como José Saramago, por exemplo. Podemos verificar a ausência de pontuação em passagens como a que se segue: “..veres a terra a girar azul no teu útero acácias chorando sangue em cima de nós ou os meus olhos sobre ti obscenos como holofotes de polícia..." (VIEIRA, 1989, p. 56). Além da ausência de pontuação, encontramos o uso de preposições que distoam completamente da norma padrão da língua portuguesa, e aí se faz necessária uma subdivisão no tocante a elas. Em algumas passagens, por exemplo, o personagem parece querer se transmutar, se transfigurar na pessoa ou objeto descrito, pois este vem sempre 
acompanhado pela preposição "em" seguida de artigo, como nos seguintes casos: "espalha os teus panfletos, vou matar nos brancos" e "E choro e tenho raiva nas minhas lágrimas ..., queria rir, rir na voz da Mimi". (VIEIRA, 1989, p.128); "E de repente, me lembro agora na terceira palavra: kikunda, traição...", “... não penso nada, me esqueci já que o Maninho morreu, que venho para contar no Paizinho" (VIEIRA, 1989, p.149); “... aprendeste as palavras no avô Paulo? (VIEIRA, 1989, p.55). Este último recurso utilizado pela escrita luandina é curioso, visto que se serve de uma preposição para fundir o discurso de um personagem no discurso de outro, num interessante jogo polifônico. Há, ainda, preposições inventadas “...que entrei de dar explicações...”( VIEIRA, 1989, p. 23); “... com depressa para por flores no campo da memória?” (VIEIRA, 1989, p. 86); a inteira ausência delas ou a supressão de termos: "...fechei a porta e ia sair embora..." (VIEIRA, 1989, p. 23) e "E um pequeno cu d'agulha serve para sair embora" (VIEIRA, 1989, p. 87).

Mas não nos prolongaremos mais, pois seria necessário um novo artigo que abordasse unicamente a subversão linguística em Nós, os do Makulusu e nosso interesse é saber como ela se opera no nível do discurso. Este se apresenta por meio de uma sintaxe "fraturada", que atua sobre ele adulterando ainda mais seu caráter fragmentário e incide também sobre sua forma. A unidade de tal discurso desvanece, obliterando o caráter sintético e conclusivo da obra, agudizando sua incompletude e dando maior autonomia às partes que se comunicam entre si e com o todo. É o que Theodor Adorno nomeia de condição melancólica da obra de arte, conforme nos explica Jaime Ginzburg (2010). Segundo Ginzburg, "a unidade da obra de arte, ao compor uma totalidade, viola o sintetizado, isto é, contraria a própria matéria da qual a forma se constitui e impede que essa matéria processe a sua condensação em uma unidade". (GINZBURG, 2010, p. 187). Essa tensão e essa ausência de síntese apontarão para um caráter de inconclusibilidade da obra, ou seja, esta não se fecha e seus elementos se articulam de diversas maneiras entre si e com o todo.

Em Nós, os do Makulusu, romance ambientado em Angola nos anos da guerra de independência, percebemos, através do discurso de Mais Velho, uma heterogeneidade incrível no campo linguístico, que é atravessado de palavras em quimbundo, língua local falada pela maioria da população negra e compreendida por muitos brancos. Está sempre presente não apenas nas falas do personagem Kibiaka, que é negro, mas também na de outros 


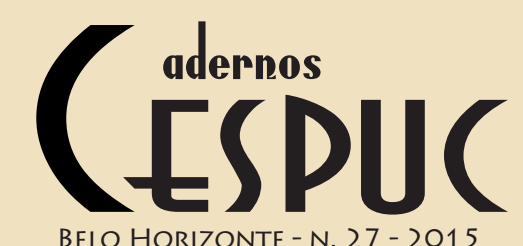

BELO HORIZONTE - N. 27 - 2015

\section{Enio GOnTIJO de LaCERDa}

personagens e, inclusive, na do narrador. Todos os enunciados proferidos por Mais Velho são "contaminados", não apenas no discurso de outrem, como foi dito acima, mas no vernáculo quimbundo. $\mathrm{O}$ próprio personagem faz questão de lembrar ao leitor "Nós, bilíngues que somos". Além disso, o próprio título da obra é bilíngue. Dois episódios interessantes acontecem quando Mais Velho está na escola e a professora lhe pergunta o nome da mãe; este lhe responde "Estrudes", motivo pelo qual é imediatamente castigado por ela por ter respondido como os negros a chamavam, em lugar do nome Maria Gertrudes. O outro é o da irmã, que se ofende ainda mais quando Mais Velho a trata usando palavras em quimbundo:

\footnotetext{
Aiuê, quente prazer de infância ver-lhe assim, dezasseis anos, quer ser uma dona das da Alta, fala só das suas amigas isto e mais aquilo e eu me meto com o que nela dói mais ter e aperta com duas cintas e, depois, come vinte e quatro pastéis de nata uns atrás dos outros: um realíssimo cu. Mas eu digo como ela se ofende mais: mataco, que é uma palavra de negros e isso sempre não me perdoará, não vai me perdoar daqui a dez anos quando por lá passar, há-de dizer que tinha razão: - Os negros?!... Seres inferiores, desprezíveis! Macacos sem rabo! ... (VIEIRA, 1989, p. 45-46).
}

Tudo isso denuncia um forte preconceito não apenas com o negro, com a cor de sua pele, mas com todos os elementos que formam sua cultura, inclusive a língua. Nessa perspectiva, não apenas o quimbundo é objeto de exclusão pela cultura branca colonial, mas a forma como os negros angolanos falam o português, um português "contaminado" com marcas de outras línguas. Questionando essa exclusão da alteridade negra e de sua língua, a narrativa de Mais Velho se constrói a partir justamente dessa "contaminação", a qual, afinal de contas, está presente e se faz notar também no discurso dos descendentes dos colonizadores.

'É interessante lembrar as observações de Deleuze e Guattari no plano da linguagem quando estes destacam a complexa escritura de Kafka, para quem, segundo os estudiosos, era necessário "estar em sua língua como um estrangeiro”. (DELEUZE; GUATRARI, 1977, p. 40). O mesmo acontece em Nós, os do Makulusu, pois Luandino Vieira, para tecer sua narrativa em português, a língua do colonizador, cerca-se de elementos linguísticos de falares locais "deformando-a", transformando-a para que esta se adapte a uma forma narrativa que contemple toda a problemática colocada em discussão nas literaturas africanas de língua portuguesa, em geral, e à literatura angolana, em particular, relativa à linguagem 
adotada pelos escritores: afinal, como os escritores destes países podem escrever sua própria história usando uma língua que não é, exatamente, a sua, mas é, antes, a língua do colonizador? Luandino Vieira, por ser filho de imigrantes portugueses, provavelmente sentiu o peso dessa realidade de forma ainda mais contundente, uma vez que reivindica, em seu próprio nome e em sua escrita, sua dupla pertença.

A fragmentação da forma, a elasticidade e a plasticidade conferidas ao tratamento da língua pela escrita luandina apontam para outro detalhe: a desterritorialização que ela promove tanto na língua portuguesa quanto no quimbundo. Deleuze e Guattari explicam que a desterritorialização se opera por meio de "linhas de fuga criadoras", cujo objetivo seria fazer ouvir a língua fora do poder. Assim, a desterritorialização promovida pela escrita luandina seria uma maneira de escrever num contexto opressor, traumático, que demanda do escritor adulterar linguagem, forma e conteúdo para traçar uma narrativa que desconfigure, desmantele completamente a centralização, a unidade de uma língua e de uma cultura que se pretendem hegemônicas em sua relação com a outra.

No romance de Luandino Vieira temos, então, além desta língua portuguesa deslocada, rasurada, a língua quimbundo também deslocada e rasurada. Ambas coexistem. O quimbundo é usado na cena do pacto e em outras muitas, assinalando sua presença na vida das personagens brancas e, mais que isso, na identidade das personagens. Por isso, além de Paizinho e, especialmente, de Kibiaka, também Mais Velho o utiliza em muitas situações, como na seguinte passagem: "Não, não era ainda a tua morte, a tua frase, por ser quase domingo para a galinha engordada, kala sanji, uatobo kala sanji..." (VIEIRA, 1989 p. 23).

Faz-se também importante salientar que o caráter fragmentado da obra aponta para a impossibilidade de resgatar o passado comum e mítico da nação e da infância, que é evocado o tempo todo na narrativa de Mais Velho, em tom nostálgico, sinalizando a busca de equilíbrio, de harmonia perante o caos da guerra no presente angolano. Aliás, o choque, o trauma gerado pela guerra será um elemento de constante tensão na rememoração de Mais Velho, tornando impraticável qualquer tentativa de equalização, de unificação do sentido, já que a narrativa é construída por um narrador perplexo diante da morte do irmão, que deseja, mais do que propor um diálogo verossímil sobre a guerra e seu impacto, expressar essa perplexidade. 
Voltando mais uma vez à questão da linguagem, a escrita literária de Luandino Vieira, em Nós, os do Makulusu, por tudo o que foi exposto até aqui, questiona a língua como instrumento de poder e, consequentemente, recusa sua imposição como instrumento de dominação. Chegamos, então, a um momento onde se faz necessário a abordagem de um tema que também está em consonância com o que foi exposto acima: as relações entre língua e poder.

Em seu ensaio Aula (1978), Roland Barthes diz que "a linguagem é uma legislação, a língua é seu código. Não vemos o poder que reside na língua, porque esquecemos que toda língua é uma classificação, e que toda classificação é opressiva". (BARTHES, 1978 , p. 12). Sendo assim, seria necessário, por parte dos escritores angolanos, driblar a linguagem, e a forma literária, para criar uma escrita que se aproximasse de sua realidade. Esta fuga para um novo padrão estilístico, com inovações nos campos sintáticos e semânticos, favorece plenamente o florescimento de uma literatura que se constrói em diálogo constante com o meio em que foi produzida. Apenas a literatura possui esta capacidade de "trapacear com a língua", pois, segundo Barthes, a literatura é, justamente, "Esta trapaça salutar, essa esquiva, esse logro magnífico que permite ouvir a língua fora do poder, no esplendor de uma revolução permanente da linguagem." (BARTHES, 1978, p. 16).

Trapaceando com a língua, utilizando-a fora do espaço de poder, encontramos a escrita luandina, que se recusa a seguir os parâmetros da língua portuguesa convencional e da literatura clássica, nos moldes de uma língua e cultura/literatura que lhe foram atribuídas. Quando Luandino Vieira se rebela contra este modo de criação literária e impõe sua escrita, assume uma atitude de resistência. Assume, também, uma postura política quando coloca em evidência a relação entre língua e poder como um instrumento de violência, na medida em que sua imposição limita, no plano da linguagem, o domínio da liberdade e da democracia. Tal como o alemão utilizado por Kafka em sua obra, também o português de Luandino Vieira adota as linhas de fuga, de libertação, de não pertencimento à língua do colonizador, mesmo que esta seja predominante na composição do texto. Deleuze e Guattari constatam tudo isso de maneira bastante significativa quando sugerem:

Servir-se do polilinguismo em sua própria língua, fazer desta um uso menor ou intensivo, opor o caráter oprimido dessa língua a seu caráter opressor, encontrar 
os pontos de não-cultura e de subdesenvolvimento, as zonas linguísticas de terceiro mundo por onde uma língua escapa. Quantos estilos, ou gêneros, ou movimentos literários, mesmo bem pequenos, só têm um sonho: preencher uma função maior da linguagem. (DELEUZE; GUATTARI, 1.977, p. 42).

Em Nós, os do Makulusu, Luandino Vieira, ao usar uma forma completamente fragmentada, uma linguagem rasurada, fraturada, com elementos absolutamente originais e, além disso, ao colocar em cena o tensionamento de duas línguas, português e quimbundo, transgredindo seu registro oficial, "africanizando" a língua portuguesa, moldando-a e inscrevendo nela a oralidade da cultura angolana, dá à sua obra um caráter caleidoscópico, de resistência, associada a um viés político, mostrando-nos, como tantos escritores africanos de língua portuguesa o fazem, que não há limites para a criação literária.

\section{ABSTRACT}

This text aims to show the artifices adopted by Luandino Vieira in the design of the language used in Nós, os do Makulusu (1989) and the relation between language, power, resistence and identity.

Key words: Luandino Vieira. Language. Power. Resistence. Identity.

\section{REFERÊNCIAS}

BAKHTIN, Mikhail. Questões de literatura e de estética. A teoria do romance. São Paulo: Editora Unesp, 1993.

BARTHES, Roland. Aula. Tradução de Leyla Perrone-Moisés. São Paulo: Cultrix 2010.

DELEUZE, Gilles; GUATTARI, Félix. Kafka, por uma literatura menor. Tradução Júlio Castañon Guimarães. Rio de Janeiro: Imago Editora Ltda, 1977.

ECO, Umberto. Seis passeios pelo bosque da ficção. Tradução Hildegard Feist. São Paulo: Companhia das Letras, 1994.

FAULKNER, William. O som e a fúria. São Paulo: Cosac \& Naify. 2004. 
FAULKNER, William. Enquanto agonizo. Traduzido por Wladir Dupont. Porto Alebre/RS: Editora L\&PM, 2009.

GUINSBURG, Jaime. Autoritarismo e literatura: a história como trauma. In. Revista eletrônica Vidya. V. 19, n. 33, p. 4352, 2000. Disponível em: http://www.periodicos.unifra.br/ index.php/VIDYA/article/view/533/523. Acesso em: 10 de junho de 2014.

GUINZBURG, Jayme. Violência e forma em Hegel e Adorno. Universidade de São Paulo, Revista Brasileira de Literatura Comparada, n. 16, 2010.

HALL, Stuart. A identidade cultural na pós-modernidade. Tradução Tomaz Tadeu da Silva, Guaracira Lopes Louro. Rio de Janeiro: DP\&A, 2006.

LABAN, Michel. José Luandino Vieira e sua obra (estudos, testemunhos, entrevistas). Lisboa: edições 70, 1980.

VIEIRA, José Luandino. Nós, os do Makulusu. Luanda: União dos Escritores Angolanos, 1989. 